\title{
ANALISA PEMILIHAN PROPELLER TIPE B-SERIES PADA KAPAL FERI RO-RO 600 GT DENGAN MENGGUNAKAN APLIKASI MATCHPRO
}

\author{
Selection Analysis of B-Series Propeller Type \\ on Ferry Ro-Ro 600 GT Vessel using Matchpro Applications
}

\author{
Habibi $^{1}$ dan Nurhadi ${ }^{2}$ \\ ${ }^{1}$ Teknik Sistem Perkapalan, FTK - ITS, Surabaya. \\ ${ }^{2}$ Balai Teknologi Hidrodinamika, BPPT, Surabaya. \\ Email: habibi_bje@yahoo.com
}

Diterima: 23 Agustus 2016; Direvisi: 23 Oktober 2016; Disetujui: 23 Nopember 2016

\begin{abstract}
Abstrak
Kondisi perairan Indonesia yang terdiri dari ribuan gugusan pulau memberikan tantangan untuk mendesain alat transportasi yang efisien dari segi pengoperasiannya. Kapal Feri Ro-Ro merupakan salah satu alternatif yang dipakai. Namun dari beberapa kasus didapatkan bahwa kapal tidak memenuhi kecepatan sesuai perencanaan. Salah satu penyebabnya adalah turunnya efisiensi dari propeller. Turunnya efisiensi propeller ini dipengaruhi oleh beberapa faktor diantaranya terjadinya kavitasi pada propeller, ketidak sesuaian mesin dan propeller yang digunakan pada saat operasional, sehingga diperlukan suatu metode engine propeller matching. Penelitian ini bertujuan untuk menganalisis tipe propeller B-series yang tepat untuk kapal Feri Ro-Ro 600 GT dengan menggunakan aplikasi Matchpro dengan database propeller dan mesin penggerak yang digunakan. Dari hasil penelitian diketahui bahwa tipe propeller B-Series yang paling efisien dipasang pada Kapal Feri Ro-Ro 600 GT adalah tipe B335.
\end{abstract}

Kata kunci: kapal feri, efisiensi propeller, Matchpro

\begin{abstract}
Indonesian maritime condition that consists of thousands of islands, provides a challenge to design an efficient transportation for operation. Ferry Ro-Ro is one of alternative that is used. But in some cases it was found that the vessel does not reach the speed according to the plan. One of the reasons is decline in the efficiency of propeller. The fall of propeller efficiency is caused by several factors, including the occurrence of cavitation of the propeller, mismatch between engine power with propeller that used during operation, so, a method of engine propeller matching is needed.This study is aimed to analyze the type of propeller B-series for Ferry Ro-Ro 600 GT, by using Matchpro application based on propeller database and engine driving that used.The result shown that the best type of efficient propeller of B-Series for Ferry Ro-Ro 600 GT is B335 type.
\end{abstract}

Keywords: ferry vessel, propeller efficiency, Matchpro

\section{PENDAHULUAN}

Kapal feri adalah kapal khusus yang dibuat atau dibangun untuk penyeberangan barang dan penumpang, dengan jarak pelayaran pendek dan dekat, dengan melintasi sungai, kawasan pelabuhan, juga sepanjang pantai atau pulau. Kapal feri beroperasi sepanjang pantai suatu pulau dan atau antar pulau yang hanya membawa sedikit kendaraan dan penumpang. 
Dalam beroperasi, suatu kapal feri setidaknya harus memiliki kemampuan untuk mempertahankan kecepatan dinas (Vs) seperti yang sudah direncanakan sejak awal. Hal ini berarti bahwa, kapal yang beroperasi dengan baik haruslah memiliki suatu rancangan sistem penggerak (propulsion system) yang dapat mengatasi keseluruhan gaya hambat (total resitance) yang terjadi agar tetap dapat mempertahankan kecepatan dinas seperti yang sudah direncanakan.

Kapal Feri Ro-Ro adalah kapal yang dibangun untuk penyebrangan kendaraan dan penumpang dengan jarak yang pendek dalam melintasi sungai atau pantai suatu pulau atau antar pulau. Sebagai produk teknologi transportasi, maka Kapal Feri Ro-Ro mempunyai ciri-ciri umum sebagai berikut:

- Geladak diisyaratkan dengan lebar yang cukup besar untuk pengangkutan kendaraan agar arus masuk keluarnya kendaraan menjadi cepat.

- Mempunyai geladak kendaraan/mobil sebagai deck kekuatan utama.

- Di atas geladak kendaraan terdapat geladak untuk muatan penumpang

- Penempatan kendaraan sedemikian rupa sehingga terlindungi dari air laut

- Mempunyai pintu rampa (ramp door) baik itu di depan dan belakang maupun di samping.

- Untuk mencukupi lebar kapal yang besar. Kapal di lengkapi dengan balok pelintang yang cukup dan juga dilengkapi dengan fender.

- Karakteristik yang lebih spesifik dari Kapal Feri Ro-Ro yaitu dimana bongkar muat secara horisontal dengan menggunakan roda dari luar dan kedalam kapal melalui rampa jembatan kapal.

- Kapal ini selain mengangkut barang juga mengangkut penumpang. (Rosmani dkk., 2013)

Kebutuhan akan Kapal Feri Ro-Ro dengan berbagai fungsinya, mengharuskan untuk rancangan sistem penggerak kapal yang efektif dan efisien. Sistem penggerak yang optimal dilakukan dengan pemilihan tipe propeller secara cermat sesuai dengan kebutuhan serta selaras dengan mesin penggerak yang akan dipasang di kapal.

\section{Perumusan dan Batasan Masalah}

Berdasarkan permasalahan yang dikemukakan sebelumnya, penulis ingin mengkaji dan menganalisis pemilihan propeller tipe $B$-Series yang akan digunakan pada Kapal Feri Ro-Ro 600 GT, dengan menggunakan aplikasi Matchpro, sehingga diketahui tipe propeller mana yang memiliki efisiensi tertinggi.

Batasan masalah dalam melakukan penelitian yang dilakukan mencakup beberapa aspek antara lain: perhitungan tahanan dan daya kapal serta pemakaian propeller tipe B-Series. Perhitungan tahanan dan power kapal dengan menggunakan hull speed yaitu program yang digunakan untuk menghitung tahanan dan power kapal. Hasil perhitungan ini ditampilkan dalam bentuk angka dan grafik. Tipe B-Series propeller yang dianalisis sesuai yang disediakan oleh database aplikasi, dalam hal ini ada 8 (delapan) tipe $B$-Series propeller yang tersedia dalam aplikasi yaitu: B335, B350, B365, B380, B440, B455, B470 dan B485. Data $B$-Series propeller ini didapatkan dari grafik data sheet open water B-Series propeller yang telah dimasukkan dalam database aplikasi program.

\section{TINJAUAN PUSTAKA}

\section{Engine Propeller Matching}

Salah satu tahapan dalam mengevaluasi desain kapal feri adalah EPM (Engine Propeller Matching). Matching point merupakan suatu titik operasi dari putaran motor penggerak kapal (engine speed) yang sedemikian hingga tepat (match) dengan karakter beban propeller, yaitu titik operasi putaran motor dimana tenaga yang diserap oleh propeller sama dengan tenaga yang dihasilkan oleh engine dan menghasilkan kecepatan kapal yang mendekati dengan kecepatan servis kapal yang direncanakan.

Secara umum kapal yang bergerak di media air dengan kecepatan tertentu, maka akan mengalami gaya hambat (resistance) yang berlawanan dengan arah gerak kapal tersebut. Besarnya gaya hambat yang terjadi harus mampu diatasi oleh gaya dorong kapal (thrust) yang dihasilkan dari kerja alat gerak kapal (propulsor). Daya yang disalurkan (Delivered Power / $\left.P_{D}\right)$ ke alat gerak kapal adalah berasal dari Daya Poros (Shaft Power / Ps), sedangkan Daya Poros sendiri bersumber dari Daya Rem (Brake Power/PB) setelah dikurangi dengan shaft losses.

\section{Karakteristik Umum Propeller pada Open Water}

Gaya dan momen yang dihasilkan oleh propeller dapat digambarkan dalam bentuk besaran pokok, yang disajikan dalam serangkaian karakteristik tak bersatuan (nondimensional). Karakteristik ini digunakan untuk menggambarkan secara umum performa dari suatu propeller. Karakteristik tersebut adalah: 
Analisa Pemilihan Propeller Tipe B-Series pada Kapal Feri Ro-Ro 600 GT dengan Menggunakan Aplikasi Matchpro

(Habibi dan Nurhadi)

Thrust Coefficient

$$
K_{T}=\frac{T}{\rho n^{2} D^{4}}
$$

Torque Coefficient

$$
K_{Q}=\frac{Q}{\rho n^{2} D^{5}}
$$

\section{Coefficient Advance}

$$
\mathrm{J}=\frac{v_{a}}{n n}
$$

Cavitation number

$$
\sigma=\frac{P_{0}-\oplus}{\frac{1}{2} \rho V^{2}}
$$

dimana :

$$
\begin{array}{ll}
\mathrm{D} & =\text { diameter } \text { propeller } \\
\mathrm{K}_{\mathrm{T}} & =\text { koefisien } \text { thrust } \\
\mathrm{K}_{\mathrm{Q}} & =\text { koefisien } \text { torque } \\
\mathrm{J} & =\text { koefisien advance } \\
\mathrm{V}_{\mathrm{a}} & =\text { kecepatan advance } \text { aliran fluida } \\
\mathrm{n} & =\text { kecepatan putar propeller } \\
\rho & =\text { massa jenis fluida } \\
\mathrm{P}_{0}-\mathrm{e} & =\text { tekanan statis fluida di daun propeller }
\end{array}
$$

\section{Interaksi Lambung Kapal dengan Propeller}

Carlton (2007), memaparkan tentang interaksi lambung kapal dan propeller (hull and propeller interaction) merupakan upaya-upaya pendekatan diatas kertas untuk mendapatkan karakteristik kinerja propeller saat beroperasi untuk kondisi di belakang kapal (behind the ship). Metode yang digunakan dengan rumusan berikut:

$$
\begin{aligned}
& T \text { ship }=\frac{\propto V a^{2}}{(1-t)(1-w)^{2}} \\
& T \text { prop }=K t x \rho x n^{2} x D^{4} \\
& T \text { prop }=T \text { ship } \\
& K_{T}=\frac{\propto V a^{2}}{(1-t)(1-w)^{2} \rho x n^{2} x D^{4}}
\end{aligned}
$$

dimana:

$$
\begin{array}{ll}
\text { Tship } & =\text { gaya yang dibutukan kapal } \\
\text { Tprop } & =\text { gaya yang dihasilkan propeller } \\
\mathrm{K}_{\mathrm{T}} & =\text { koefisien } \text { thrust } \\
t & =\text { thrust deduction factor } \\
w & =\text { wake factor }
\end{array}
$$

$$
\begin{array}{ll}
\alpha & =0.5 \cdot \rho \cdot \mathrm{C}_{\mathrm{T}} \mathrm{S} \\
\mathrm{C}_{\mathrm{T}} & =\text { total resistance coefficient } \\
\mathrm{S} & =\text { ship wetted surface area } \\
\mathrm{n} & =\text { kecepatan putar propeller }
\end{array}
$$

\section{METODOLOGI}

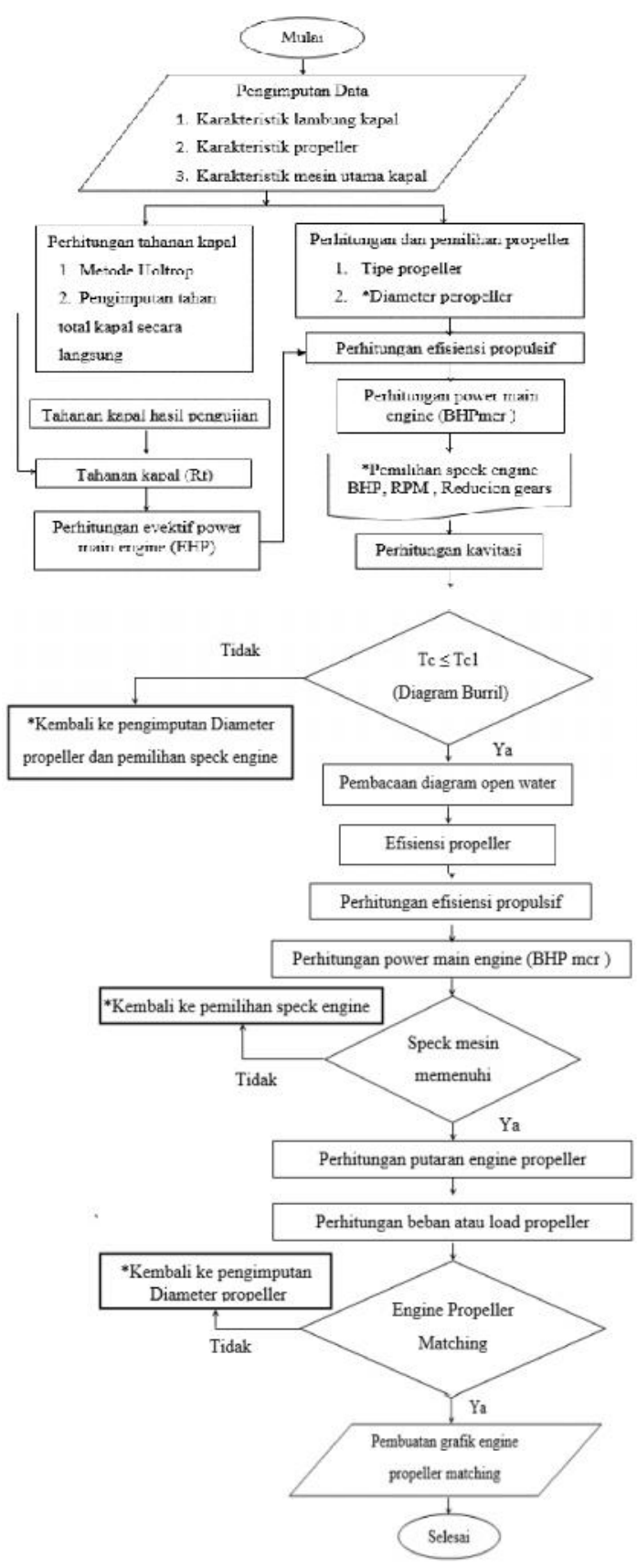

Gambar 1. Flow chart penelitian 
Untuk mendapatkan match point antara lambung kapal, propeller dan mesin utama kapal, yaitu titik dimana daya yang diserap oleh propeller sama dengan daya yang dihasilkan oleh mesin kapal sehingga dihasilkan kecepatan kapal yang mendekati dengan kecepatan servis sesuai yang direncanakan, sedangkan langkah pengerjaan dengan aplikasi Matchpro dapat dipresentasikan seperti Gambar 1.

Data-data yang dikumpulkan selanjutnya akan diolah, adapun tahapan dalam analisa data meliputi:

1. Penyajian data kapal

2. Perhitungan main engine power

3. Perhitungan karakteristik propeller

4. Perhitungan putaran engine

5. Perhitungan propeller load

6. Penentuan engine propeller matcing

7. Grafik engine propeller matcing

\section{HASIL DAN PEMBAHASAN}

Jenis penelitian yang digunakan adalah kuantitatif dan non eksperimental dengan menggunakan aplikasi Matchpro. Jenis data yang digunakan dalam penelitian ini adalah data sekunder, yaitu data perhitungan Kapal Feri Ro-Ro 600 GT yang telah ada sebelumnya. Aplikasi yang digunakan untuk menganalisa pemilihan tipe propeller yang dipasang pada Kapal Feri Ro-Ro 600 GT adalah aplikasi Matchpro.

\section{Aplikasi Matchpro}

Aplikasi Matchpro adalah aplikasi berekstensi java yang dikompilasi menjadi file class, yaitu byte code yang bisa dijalankan di semua Java Virtual Machine, tidak peduli apapun $O S$-nya ataupun arsitektur processor-nya.

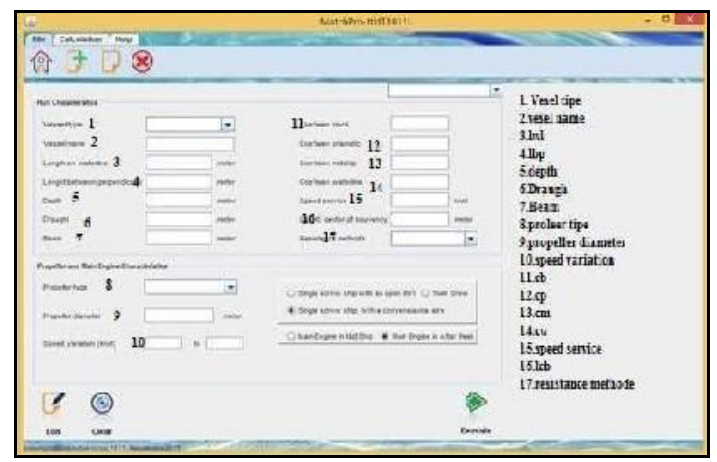

Gambar 2. Tampilan Aplikasi Matchpro

Aplikasi ini dikembangkan pada awal tahun 2016 di Laboratorium Komputer Pascasarjana Fakultas Teknik Kelautan, Institut Teknologi Sepuluh Nopember. Aplikasi Matchpro di desain untuk membantu melakukan analisa hubungan antara hull, engine dan propeller satu sama lain, sehingga akan memberikan data yang akurat berhubungan dengan efisiensi engine propeller matching. Tampilan utama aplikasi dapat dilihat pada Gambar 2.

\section{Peng-input-an Data Kapal dan Data Mesin}

Proses pengerjaan penelitian ini dimulai dengan peng-input-an data kapal dan data mesin utama Kapal Feri Ro-Ro yang digunakan. Peng-input-an data-data kapal dilihat pada Gambar 2. Adapun data kapal yang di input-kan dapat dilihat pada Tabel 1. Adapun data hasil perhitungan tahanan kapal yang merupakan data input-an dapat dilihat pada Tabel 2.

Tabel 1. Tabel dimensi Kapal Feri Ro-Ro 600GT

\begin{tabular}{ccc|c}
\hline No. & Item & Ukuran Kapal & Satuan \\
\hline $\mathbf{1}$ & LOA & 50,070 & meter \\
\hline $\mathbf{2}$ & LWL & 48,596 & meter \\
$\mathbf{3}$ & LBP & 46,780 & meter \\
\hline $\mathbf{4}$ & $\mathrm{B}$ & 13,800 & meter \\
\hline $\mathbf{5}$ & $\mathrm{H}$ & 4,140 & meter \\
\hline $\mathbf{6}$ & $\mathrm{T}$ & 2,760 & meter \\
$\mathbf{7}$ & $\mathrm{Cb}$ & 0,602 & \\
$\mathbf{8}$ & $\mathrm{Cm}$ & 0,770 & \\
\hline $\mathbf{9}$ & $\mathrm{Cp}$ & 0,782 & \\
\hline $\mathbf{1 0}$ & $\mathrm{CW}$ & 0,894 & \\
\hline $\mathbf{1 1}$ & Volume & $1.110,35$ & meter \\
\hline $\mathbf{1 2}$ & LCB & 0,355 & meter \\
\hline $\mathbf{1 3}$ & Vs & 13.5 & Knot $^{3}$ \\
\hline
\end{tabular}

Sumber: Rosmani, 2013

Tabel 2. Tabel tahanan kapal hasil perhitungan dengan software

\begin{tabular}{ccc}
\hline No. & $\begin{array}{c}\text { Variasi } \\
\text { Kecepatan } \\
\text { (Knot) }\end{array}$ & Resistance $(\mathbf{k N})$ \\
\hline $\mathbf{1}$ & 11.50 & 70.05 \\
\hline $\mathbf{2}$ & 11.75 & 75.50 \\
\hline $\mathbf{3}$ & 12,00 & 81.53 \\
\hline $\mathbf{4}$ & 13.00 & 122.45 \\
$\mathbf{5}$ & 13.50 & 156.56 \\
\hline $\mathbf{6}$ & 13.75 & 175.57 \\
\hline
\end{tabular}

Sumber: Rosmani, 2013 
Analisa Pemilihan Propeller Tipe B-Series pada Kapal Feri Ro-Ro 600 GT dengan Menggunakan Aplikasi Matchpro (Habibi dan Nurhadi)

Berdasarkan hasil perhitungan tahanan Kapal Feri Ro-Ro 600 GT dengan software, maka perkiraan kasar kebutuhan daya pada kecepatan 13.5 knot adalah:

$\mathrm{P}_{\mathrm{E}}=\mathrm{R}_{\mathrm{T}} * \mathrm{Vs}$

$\mathrm{P}_{\mathrm{B}}=\mathrm{P}_{\mathrm{E}} /\left(\eta_{\mathrm{h}} \times \eta_{\mathrm{p}} \times \eta_{\mathrm{s}} \times \eta_{\mathrm{m}}\right) / 0.98 / 0.85$

$\mathrm{P}_{\mathrm{B}}=2249.16 \mathrm{~kW}$.

Dari perhitungan tersebut maka pada penelitian ini akan dipasang mesin kapal dengan spesifikasi sebagai berikut:

$\begin{array}{ll}\text { Merek } & : \text { Caterpillar } \\ \text { Model } & : \text { M32C } \\ \text { Power } & : 2250 \mathrm{~kW} \\ \text { Bore } & : 18.11 \text { inch } \\ \text { Stroke } & : 514 \text { inch } \\ \text { Rpm } & : 600 \mathrm{Rpm}\end{array}$

\section{Seleksi Tipe Propeller}

Penyeleksian tipe propeller dilakukan dengan cara mempertimbangkan kavitasi yang coba dihitung untuk semua tipe propeller. Aplikasi Matchpro memberikan list propeller yang cocok untuk dipasang di Kapal Feri Ro-Ro 600 GT. Daftar propeller dapat dilihat pada Tabel 3.

Nilai $\tau \mathrm{c}$ hitung adalah hasil perhitungan $\tau \mathrm{c}$ berdasarkan rumus koefisien Burril (1943) untuk memperkirakan terjadinya kavitasi, $t c=\frac{T / A p}{0.5 \rho V_{\tau}^{2}}$, dimana:

$\tau \mathrm{c}=$ nilai kritis koefisien.

$T=$ gaya dorong baling-baling.

$A_{P}=$ luas proyeksi daun.

$V_{R}=$ kecepatan relatif air pada 0.7 jari-jari ujung $R$

Nilai $\tau$ graph adalah nilai $\tau c$ dalam diagram Burril yang didapatkan dengan menghitung nilai $\tau \mathrm{c}$ pada 0.7R yang dipotongkan pada nilai upper limit.

Apabila perhitungan nilai $\tau c$ propeller lebih kecil daripada nilai $\tau c$ Burril maka kemungkinan kecil propeller akan mengalami kavitasi.

Dalam hal pemilihan propeller, beberapa parameter dibawah ini harus dipenuhi:

- Diameter propeller harus lebih kecil dari 0,7 T.

- Tidak terjadi kavitasi pada propeller.

- Propeller yang dipilih mempunyai efisiensi yang paling bagus.

- $\quad$ Bhp MCR harus lebih kecil dari daya mesin yang dipasang di kapal Feri Ro-Ro 600 GT.

Melihat ketentuan tersebut, maka propeller yang dipilih adalah propeller dengan tipe B335 dan B440 dengan beberapa alasan antara lain:
- Dari hasi perhitungan kavitasi yang ada pada tabel 3, dapat dilihat bahwa semua tipe propeller yang di pilih aplikasi tidak mengalami kavitasi dimana ( $\tau$ c hit $<\tau c$ graph), namun selisih tertinggi terdapat pada type B335, B440 dan B455.

- Selain tidak terjadi kavitasi, tipe propeller B335, dan B440 memiliki effisiensi propeller tertinggi dimana tipe ini mempunyai nilai effisiensi 0.727 dan 0.71 .

Tabel 3. Tabel list propeller

\begin{tabular}{lcccccc}
\hline T.prop & Max.D & Eff & $\begin{array}{c}\text { Bhp Mcr } \\
(\mathbf{k W})\end{array}$ & $\begin{array}{c}\text { TC } \\
\text { hitung }\end{array}$ & $\begin{array}{c}\tau \mathrm{c} \\
\text { graph }\end{array}$ \\
\hline B335 & 1.93 & 0.727 & 1952.26 & 0.18325 & 0.50123 \\
\hline B350 & 1.93 & 0.709 & 2001.96 & 0.13093 & 0.28976 \\
\hline B365 & 1.93 & 0.679 & 2087.89 & 0.11177 & 0.22588 \\
\hline B380 & 1.93 & 0.663 & 2139.00 & 0.14276 & 0.33371 \\
\hline B440 & 1.93 & 0.71 & 2026.21 & 0.21919 & 0.69526 \\
\hline B455 & 1.93 & 0.70 & 2027.60 & 0.18999 & 0.53496 \\
\hline B470 & 1.93 & 0.695 & 2042.19 & 0.12075 & 0.25582 \\
\hline B485 & 1.93 & 0.661 & 2147.74 & 0.1108 & 0.22266 \\
\hline
\end{tabular}

Sumber: Data olahan aplikasi Matchpro

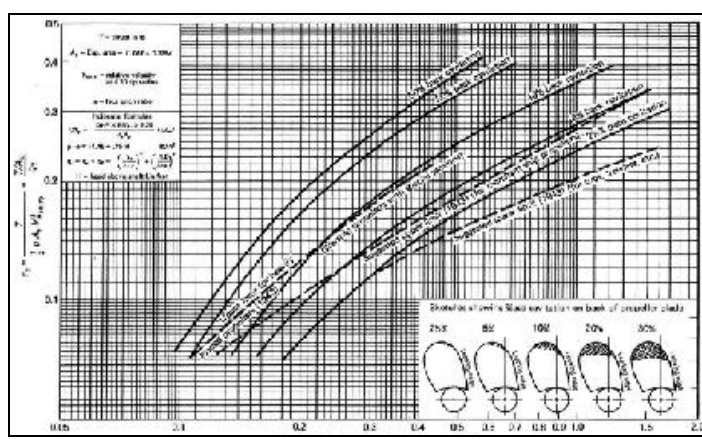

Gambar 3. Diagram kavitasi Burril

(sumber: Marine Propellers and Propulsion)

\section{Perhitungan Power Engine}

Hasil perhitungan kebutuhan power dengan effisiensi propeller behind the ship yaitu efisiensi yang diukur pada posisi propeller di buritan kapal pada kecepatan dinas kapal, pada perhitungan ini dapat dilihat pada Tabel 4 .

Tabel 4. Tabel hasil perhitungan kebutuhan daya

\begin{tabular}{c|cc}
\hline Tipe propeller & BHP mcr $(\mathbf{k W})$ & \%MCR \\
\hline B335 & 1952.26 & 86.77 \\
\hline B440 & 2026.21 & 90.05 \\
\hline
\end{tabular}

Sumber: Data olahan aplikasi Matchpro 
Pertimbangan dengan melihat persentase daya yang dibutuhkan untuk mendapatkan kecepatan dinas Kapal Feri Ro-Ro 600 GT pada kondisi sea margin yaitu 13.5 knot, maka dipililah tipe B335 dengan pertimbangan bahwa persentase kebutuhan daya yang dibutuhkan lebih kecil yaitu $86.77 \%$ dibandingkan dengan tipe B440 yaitu sekitar 90.05\%. Artinya tipe propeller B335 hanya membutuhkan sekitar 1952.26 $\mathrm{kW}$ power dari $2250 \mathrm{~kW}$ power main engine yang di pasang di Kapal Feri Ro-Ro 600 GT.

\section{Penggambaran Grafik KT-J dan Diagram Open Water Tipe B335}

Interaksi lambung kapal dan propeller (hull and propeller interaction) merupakan upaya-upaya pendekatan "diatas kertas" untuk mendapatkan karakteristik kinerja propeller saat beroperasi untuk kondisi behind the ship. (Adji, 2005). Hasil perhitungan dapat dilihat pada Tabel 5.

Tabel 5. Tabel data KT-J dan kurva open water

\begin{tabular}{clcccc}
\hline $\mathbf{J}$ & KT & 10KQ & Eff & KT-Service & KT-Clean \\
\hline $\mathbf{0}$ & 0.4063 & 0.57562 & 0 & 0 & 0 \\
\hline $\mathbf{0 . 1}$ & 0.3855 & 0.55991 & 0.10964 & 0.02352 & 0.0196 \\
$\mathbf{0 . 2}$ & 0.362 & 0.5388 & 0.21397 & 0.09408 & 0.0784 \\
$\mathbf{0 . 3}$ & 0.3357 & 0.51229 & 0.31308 & 0.21168 & 0.1764 \\
$\mathbf{0 . 4}$ & 0.3067 & 0.48037 & 0.40675 & 0.37631 & 0.3136 \\
$\mathbf{0 . 5}$ & 0.2750 & 0.44305 & 0.4943 & 0.58799 & 0.48999 \\
$\mathbf{0 . 6}$ & 0.2406 & 0.40033 & 0.57431 & 0.84671 & 0.70559 \\
\hline $\mathbf{0 . 7}$ & 0.2035 & 0.35221 & 0.64404 & 1.15246 & 0.96039 \\
\hline
\end{tabular}

Sumber: Data olahan aplikasi Matchpro

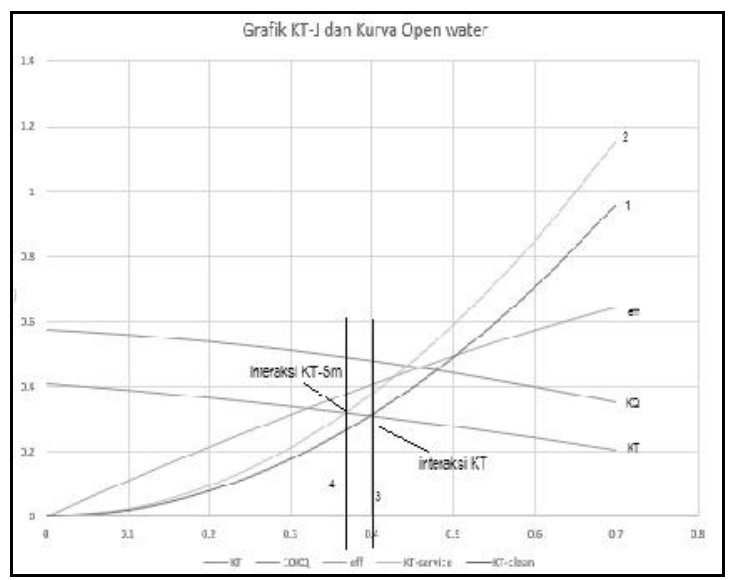

Gambar 4. Grafik KT-J dan Kurva open water
Kurva [1] merupakan trendline koefisien propeller thrust untuk trial conditions. Dan dengan melihat keadaan kurva $J$ [3] diperoleh harga koefisien propeller torque, KQ pada kondisi trial. Sedangkan, Kurva [2] adalah trendline dari propeller thrust coefficient pada kondisi hull service margin dan dengan menarik kurva $J$ [4] sedemikian hingga melewati titik KT-SM, maka diperoleh koefisien torsi propeller, KQ-SM, pada kondisi hull service margin. Selanjutnya, kedua angka KQ dan KQ-SM inilah yang digunakan untuk menentukan karakteristik beban propeller (propeller load characteristics).

Pembacaan titik potong antara KT dengan KT-service (rough water condition) dan KT-clean (calm water condition) tersebut dilakukan secara otomatis oleh aplikasi, yaitu nilai J, KT, KQ dan effisiensi, dimana hasil dapat dilihat pada Tabel 6 . Dari pembacaan grafik terlihat bahwa pada kondisi operasional efisiensi propeller menurun menjadi sekitar $0.38-0.4$.

Tabel 6. Tabel pembacaan berbagai nilai oleh aplikasi

\begin{tabular}{cccccc}
\hline Condition & J & KT & 10KQ & Eff \\
\hline Rough water & 0.37 & 0.32 & 0.49 & 0.38 \\
Calm water & 0.4 & 0.31 & 0.48 & 0.4 \\
\hline
\end{tabular}

Sumber: Data olahan aplikasi Matchpro

dimana:

$\mathrm{KT}=$ koefisien propeller thrust

$\mathrm{KQ}=$ koefisien propeller torque

$\mathrm{J} \quad=$ koefisien advanced

Eff $=$ efisiensi propeller pada kondisi open water

\section{KESIMPULAN}

Dari hasil dan pembahasan yang telah dilakukan dapat diambil suatu kesimpulan bahwa dengan menggunakan aplikasi Matchpro dari beberapa propeller tipe $B$-series yang paling efisien untuk dipasang pada Kapal Feri Ro-Ro 600 GT adalah tipe B335. Pemilihan propeller tipe ini sesuai dengan ketentuan bahwa diameter propeller yg dipilih memenuhi persyaratan diameter maksimum, tidak terjadi kavitasi pada propeller berdasarkan perhitungan pada diagram burril, serta mempunyai efisiensi yang paling baik. 
Analisa Pemilihan Propeller Tipe B-Series pada Kapal Feri Ro-Ro 600 GT dengan Menggunakan Aplikasi Matchpro

(Habibi dan Nurhadi)

\section{DAFTAR PUSTAKA}

Carlton, J. S. (2007). Marine Propellers and Propulsion, United Kingdom, Elsevier, Oxford.

Harvald, Sv. Aa. (1992). Tahanan dan Propulsi Kapal, Surabaya, Airlangga University Press.

Kristensen, Hans Otto. (2013). Prediction of Resistance and Propulsion Power of Ships, University of Southern Denmark, Work package 2 Report no. 04, DTU.

Rosmani, dkk. (2013). Pengaruh bentuk lambung kapal Terhadap tahanan kapal, Proceeding Hasil Penelitian, Fakultas Teknik Universitas Hassannudin, ISBN: 978-979-127255-0-6.

Surjo W. Adji. (2005). Engine Propeller Matching [Online]Available: its.ac.id/ambilfile.php?idp=87. 